Jurnal Bina Manajemen, September 2021, Vol. 10, No. 1 Hal 229 - 245

\title{
PENGARUH KUALITAS PELAYANAN DAN HARGA TERHADAP KEPUTUSAN PEMBELIAN PADA KEDAI KIRANI COFFEE
}

\author{
Abdul Mukti \\ Sekolah Tinggi Ilmu Ekonomi Bima \\ abdulmukti17.stiebima@gmail.com \\ Kartin Aprianti \\ Sekolah Tinggi Ilmu Ekonomi Bima \\ kartinaprianti93@gmail.com
}

\begin{abstract}
This study aims to a) determine whether there is an effect of service quality on purchasing decisions at Kedai Kirani Coffee, b) knowing whether there is an effect of price on purchasing decisions at Kedai Kirani Coffee, c) knowing whether there is an influence of service quality and price on purchasing decisions at Kirani Coffee shop. This research is an associative study which aims to determine the effect of service quality and price partially and simultaneously on purchasing decisions at Kedai Kirani Coffee. The population in this study were all consumers who had visited Kedai Kirana Coffee. According to Aminulah (2013), the number of samples in associative research is 50 people. So that in this study a sample of 50 respondents. The sampling technique used by researchers in this study was purposive sampling technique. Purposive sampling is a sampling technique with certain considerations, in this study, namely consumers who have visited at Kedai Kirana Coffee. Data collection techniques used in this study are observation, questionnaires and literature study. The data analysis techniques used are validity test, reliability test, classic assumption test, multiple linear regression, multiple correlation coefficient, determination test and $t$ test (partial) and $F$ test. The results show that a) Service quality has a positive and significant effect. Against Purchasing Decisions at Kedai Kirani Coffee, b) Prices have a positive and significant effect on purchasing decisions at Kedai Kirani Coffee, c) Service quality and prices simultaneously have a positive and significant effect on purchase decisions at Kedai Kirani Coffee.
\end{abstract}

Keywords: Service Quality, Price, Purchase Decision

\begin{abstract}
ABSTRAK
Penelitian ini memliki tujuan untuk a)mengetahui ada tidaknya pengaruh kualitas pelayanan terhadap keputusan pembelian pada Kedai Kirani Coffee, b) mengetahui ada tidaknya pengaruh harga terhadap keputusan pembelian pada Kedai Kirani Coffee, c) mengetahui ada tidaknya pengaruh kualitas pelayanan dan harga terhadap keputusan pembelian pada Kedai Kirani Coffee. Penelitian ini merupakan penelitian asosiatif yang bertujuan untuk mengetahui pengaruh kualitas pelayanan dan harga secara parsial dan simultan terhadap Keputusan Pembelian pada Kedai Kirani Coffee. Populasi dalam penelitian ini adalah seluruh konsumen yang pernah berkunjung di Kedai Kirana Coffee. Menurut Aminulah (2013), menyetakan bahwa jumlah sampel pada penelitian asosiatif sebanyak 50 orang. Sehingga dalam penelitian ini sampel sebanyak 50 responden. Teknik sampling yang digunakan oleh peneliti dalam penelitian ini adalah pengambilan teknik sampling purposive sampling. Purposive sampling adalah teknik penentuan sampel dengan pertimbangan tertentu, dalam penelitian ini yaitu konsumen yang
\end{abstract}




\section{Pengaruh Kualitas Pelayanan dan Harga Terhadap Keputusan Pembelian Pada Kedai Kirani Coffeee}

pernah berkunjung di di Kedai Kirana Coffee.Teknik pengumpulan data yang digunakan dalam penelitian ini yaitu observasi, kuesioner dan studi pustaka. Teknik analisis data yang digunakan yaitu uji validitas, uji reliabilitas,, uji asumsi klasik, regresi linier berganda, koefisien kolerasi berganda , uji determinasi dan uji t ( parsial) dan uji F. Hasil penelitian menunjukkan bahwa a) Kualitas Pelayanan Berpengaruh Positif dan Signifikan Terhadap Keputasan Pembelian pada Kedai Kirani Coffee, b) harga Berpengaruh Positif dan Signifikan Terhadap Keputusan Pembelian pada Kedai Kirani Coffee, c) Kualitas Pelayanan dan harga secara simultan Berpengaruh Positif dan Signifikan Terhadap Keputasan Pembelian pada Kedai Kirani Coffee. Kata kunci: Kualitas pelayanan, Harga, Keputusan Pembelian

\section{PENDAHULUAN}

Perkembangan ekonomi di Indonesia telah menuju ke arah yang lebih baik, sejalan dengan perkembangan dunia bisnis, semakin banyak pelaku bisnis membuka dan mengembangkan bisnis mereka. Bisnis kuliner akhirakhir ini sedang menunjukan perkembangan yang pesat perkembangannya dipengaruhi oleh berbagai faktor, seperti: demografi, tingkat ekonomi yang meningkat, serta gaya hidup masyarakat. Hal ini dapat dilihat dari menjamurnya bisnis kuliner dengan berbagai konsep, seperti konsep Restoran keluarga, Warung kaki lima, hingga Distro, Cafe, dan Kedai. Saat ini masyarakat cenderung lebih memiliki kesibukan dan mobilitas yang tinggi. Mereka umumnya lebih sering menghabiskan waktu diluar rumah. Karena alasan kepraktisan dan kenyamanan, mereka biasanya mengunjungi tempat-tempat makan untuk berkumpul bersama keluarga dan teman, bertemu klien, atau hanya sekedar untuk bersantai ditengah kesibukan mereka. Kedai merupakan salah satu tempat yang banyak dipilih. Kedai dinilai tidak hanya menawarkan makanan dan minuman saja, tetapi juga menawarkan fasilitas yang dapat memberikan kenyamanan bagi pengunjungnya. Tidak heran bila para pengunjung kedai bisa menghabiskan waktu berjam-jam berada disana. Selain terlibat perbincangan santai, sebagian pengunjung juga menggunakan kedai sebagai tempat menyelesaikan tugas atau pekerjaan. Coffee merupakan komoditi unggulan di negara ini, ditandai dengan maraknya pembukan kedai- kedai di berbagai tempat. Persangan bisnis yang ada, juga membuat kedai kopi semakin ditutur agar lebih cepet dalam hal menarik konsumen. Kedai Coffee yang mempunyai konsep pemasaran perlu mencermati perilaku konsumen dan faktr-faktor yang mempenggarui keputusan pembeliannya dalam usaha-usaha pemasaransebuah produk yang dilakukan. Syarat yang dipenuhi oleh para pelaku usaha agar dapat mencapai keunggulan bersaing adalah setiap pelaku usaha berupaya menciptakan dan 
mempertahankan barang dan jasa yang diinginkan konsumen. Setiap perusahaan pada umumnya menginginkan keberhasilan dalam menjalankan usahanya. Oleh karena itu, suatu perusahaan tidak dapat bertahan tanpa adanya transaksi pembelian. Perusahaan harus memasarkan barang atau jasa yang dihasilkan kepada konsumen agar perusahaan dapat terus bertahan dan bersaing dengan perusahaan lain. Dalam persaingan bisnis Coffee yang semakin marak saat ini, setiap pelaku bisnis termasuk pelaku bisnis Coffee harus dapat mempertahankan kelangsungan dari bisnis Coffee yang dijalankan. Agar dapat bertahan dan sukses dalam bisnis Coffee, suatu perusahaan harus dapat mempertimbangkan apa yang membuat konsumen menjadi tertarik untuk memutuskan membeli Coffee di Kedai Coffee. (Kurniawan \& Sari, 2017) menjelaskan keputusan pembelian adalah tahap dalam proses pengambilan keputusan pembeli di mana konsumen benar-benar membeli. Pada intinya walaupun pemasar atau konsumen sering mengacu pada pilihan antara produk, merek dan tempat pembelian, proses pembelian biasanya juga dipengaruhi oleh hubungan baik dengan produsen. Selanjutnya, dikatakan bahwa keputusan pembelian konsumen individu dipengaruhi oleh beberapa tahap sebagai berikut:
Pengenalan masalah, pencarian informasi, evaluasi alternatif, keputusan pembelian, perilaku paca pembelian. Adapun faktor yang mempengaruhi seseorang melakukan pembelian antara lain adalah kualitas pelayanan dan harga produk. Kualitas pelayanan membuat konsumen betah berlama-lama dan harga yang sesuai membuat konsumen loyal untuk melakukan pembelian. Menurut Oktaviani (2013) Kualitas pelayanan yang baik akan meningkatkan pemasaran karena konsumen akan termotivasi untuk menyebarkan cerita baik tentang pelayanan atau bisnis kepada orang lain. Menurut Ryono dan Erlik (2018), harga adalah Sejumlah uang yang dibebankan atas suatu barang atau jasa atau jumlah dari nilai uang yang ditukar konsumen atas manfaat - manfaat karena memiliki atau menggunakan produk atau jasa tersebut. Preferensi konsumen salah satu yang membuat keputusan membeli adalah faktor hargaselain karena kualitas pelayanan yang diberikan. Kedai Kirani Coffee adalah salah satu usaha yang bergerak di bidang usaha minuman Coffee, yang berlokasi di Donggobolo, Kecamatan Woha. Dalam upaya menciptakan keputusan pembelian yang tinggi masih terkendala kualitas pelayanan yang kurang baik. Berdasarkan observasi awal peneliti menemukan masih 


\section{Pengaruh Kualitas Pelayanan dan Harga Terhadap Keputusan Pembelian \\ Pada Kedai Kirani Coffeee}

terdapatnya sejumlah keluhan konsumen yang berkaitan dengan kualitas pelayanan yang diberikan Kedai Kirani Coffee, seperti lamanyamenunggu pesanan datang sehingga membuat pengunjung mudah bosan selain itu ada beberapa karyawan yang kurang ramah dan kurang senyum kepada pengunjung. Bebeerapa hal lain juga masih adanya beberapa karyawan berpakaian yang kurang rapi, dan kelezatan masakan dirasa kurang oleh beberapa pengunjung. Jika kualitas pelayanan yang diharapkan tidak sesuai dengan kenyataannya maka konsumen tersebut tidak akan kembali menggunakan jasa yang ditawarkan Kedai Kirani Coffee. Apabila hal ini terjadi, maka keputusan pembelian konsumen menjadi rendah. Selain

\section{TELAAH LITERATUR}

\section{Kualitas Pelayanan}

Menurut Tjiptono (Rachman, 2017) menyatakan bahwa Kualitas pelayanan adalah ukuran seberapa bagus tingkat layanan yang diberikan mampu sesuai dengan ekspektasi konsumen. Menurut (Riyono \& Budiharja, 2016) kualitas pelayanan adalah tindakan yang dilakukan oleh penjual kepada konsumen untuk memenuhi kebutuhan dan keinginan para konsumen. Hal ini sejalan dengan yang dikemukakan oleh (Irzaldi, Yazid, Hidaya, \& Wahyu, 2020) kualitas pelayanan adalah masalah kualitas pelayanan, harga pun menjadi pertimbangan bagi konsumen / pengunjung Kedai Kirani Coffee yaitu harga yang lebih mahal dibandingkan Kedai Coffee yang lain .beberapa pengunjung juga mengeluhkan harga yang tidak sesuai dengan rasa Coffee yang diberikan oleh Kedai Kirani Coffee. Hal ini dapat menjadi kendala dalam upaya menciptakan keputusan pembelian di Kedai Kirani Coffee. Jika harga yang ditawarkan oleh Kedai Kirani Coffee lebih mahal jika dibandingkan dengan kedai setara lainnya, maka konsumen akan berpikir kembali untuk melakukan pembelian pada Kedai Kirani Coffee, yang dapat mengakibatkan Kedai Kirani Coffee akan kehilangan konsumen.

upaya untuk memenuhi kebutuhan yang disertai dengan keinginan konsumen, serta ketepatan cara penyampaiannya supaya dapat memenuhi harapan dan kepuasan konsumen tersebut. Tjiptono (Rachman, 2017) mengungkapkan ada terdapat lima indikator dominan atau penentu kualitas pelayanan jasa, kelima faktor dominan tersebut diantarnya yaitu:

a. Berwujud (Tangible), yaitu berupa penampilan fisik, peralatan dan berbagai materi komunikasi yang baik. 
b. Empati (Empathy), yaitu kesediaan karyawan dan pengusaha untuk lebih peduli memberikan perhatian secara pribadi kepada pengunjung. Misalnya karyawan harus mencoba menempatkan diri sebagai konsumen. Jika konsumen mengeluh maka harus dicari solusi segera, agar selalu terjaga hubungan harmonis, dengan menunjukan rasa peduli yang tulus. Dengan cara perhatian yang diberikan para karyawan dalam melayani dan memberikan tanggapan atas keluhan parakonsumen.

c. Cepat tanggap (Responsiveness), yaitu kemauan dari karyawan dan pengusaha untuk membantu konsumen dan memberikan jasa dengan cepat serta mendengar dan mengatasi keluhan konsumen. Dengan cara keinginan para karyawan dalam membantu dan memberikan pelayanan dengan tanggap, kemampuan memberikan pelayanan dengan cepat dan benar, kesigapan para karyawan untuk ramah pada setiap

\section{Harga}

Menurut (Irzaldi, Yazid, Hidaya, \& Wahyu, 2020) Harga adalah jumlah uang (ditambah beberapa barang kalau mungkin) yang dibutuhkan untuk mendapatkan sejumlah kombinasi dari barang beserta pelayanannya. Kotler (Rachman, 2017) juga menjelaskan konsumen, kesigapan para karyawan untuk bekerja sama dengan konsumen.

d. Keandalan (Reliability), yaitu kemampuan untuk memberikan jasa sesuai dengan yang dijanjikan, terpercaya dan akurat, serta konsisten. Contoh dalam hal ini antara lain, kemampuan karyawan dalam memberikan pelayanan yang terbaik, kemampuan karyawan dalam menangani kebutuhan konsumen dengan cepat dan benar, kemampuan perusahaan dalam memberikan pelayanan yang baik sesuai dengan harapan konsumen.

e. Kepastian (Assurance), yaitu berupa kemampuan karyawan untuk menimbulkan keyakinan dan kepercayaan terhadap janji yang telah dikemukakan kepada konsumen. Contoh dalam hal ini antara lain, pengetahuan dan keterampilan karyawan dalam menjalankan tugasnya, karyawan dapat diandalkan, karyawan dapat memberikan kepercayaan kepada konsumen, karyawan memiliki keahlian teknis yang baik.

bahwa Harga adalah jumlah uang yang dibebankan untuk produk atau jasa, atau lebih jelasnya adalah jumlah dari semua nilai yang diberikan oleh pelanggan untuk mendapatkan sebuah manfaat dengan memiliki atau menggunakan sebuah produk 


\section{Pengaruh Kualitas Pelayanan dan Harga Terhadap Keputusan Pembelian \\ Pada Kedai Kirani Coffeee}

atau jasa. Menurut (Kurniawan \& Sari, 2017) Jika konsumen merasa cocok dengan harga yang ditawarkan, maka mereka akan cenderung melakukan pembelian ulang untuk produk yang sama. Terdapat empat indikator ukuran yang mencirikan harga menurut Kotler dan Amstrong (Rachman, 2017) yaitu sebagai berikut:

a. Keterjangkaun Harga. Konsumen bisa menjangkau harga yang telah ditetapkan oleh perusahaan. Produk biasanya ada beberapa jenis dalam satu merek harganya juga berbeda dari yang termurah sampai termahal. Dengan harga yang di tetapkan para konsumen banyak yang membeli produk.

b. Kesesuaian harga dengan kualitas produk. Harga sering dijadikan sebagai indikator kualitas bagi konsumen orang sering memilih harga yang lebih tinggi diantara dua barang karena mereka melihat adanya perbedaan kualitas. Apabila harga lebih tinggi orang cenderung beranggapan bahwa kualitasnya juga lebih baik.

c. Kesesuaian harga dengan manfaat. Konsumen memutuskan membeli suatu

\section{Keputusan Pembelian}

(Aisyah, Agustiawan, Nurwanita, \& Fatma, 2020) menjelaskan keputusan pembelian didefinisikan sebagai sebuah pilihan dari dua produk jika manfaat yang dirasakan lebih besar atau sama dengan yang telah dikeluarkan untuk mendapatkannya. Jika konsumen merasakan manfaat produk lebih kecil dari uang yang dikeluarkan maka konsumen akan beranggapan bahwa produk tersebut mahal dan konsumen akan berpikir dua kali untuk melakukan pembelian ulang

d. Harga sesuai kemampuan atau daya saing harga. Konsumen sering membandingkan harga suatu produk dengan produk lainnya. Dalam hal ini mahal-murahnya suatu produk sangat dipertimbangkan oleh konsumen pada saat akan membeli produk tersebut. Misalnya: harga lebih murah dari pesaing. Berdasarkan dari ke empat dimensi dan indikator harga di atas, maka dapat disimpulkan bahwa dalam menentukan harga suatu produk setiap perusahaan harus mempertimbangkan keterjangkauan harga bagi konsumen, kesesuaian harga dengan kualitas produk dan manfaat yang di rasakan konsumen tanpa mengeluarkan biaya yang lebih besar saat akan membeli produk tersebut.

atau lebih alternatif pilihan. Menurut Tjiptono (Rachman, 2017) keputusan pembelian adalah sebuah proses dimana 
konsumen mengenal masalahnya, mencari informasi mengenai produk atau merek tertentu dan mengevaluasi secara baik masing-masing alternatif tersebut dapat memecahkan masalahnya, yang kemudian mengarah kepada keputusan pembelian. Kotler (Rachman, 2017) juga mengemukakan hal yang sama yaitu Keputusan pembelian adalah keputusan yang diambil konsumen untuk melakukan pembelian suatu produk yang diawali dengan pengenalan kebutuhan, mendapatkan informasi, menilai dan membandingkan beberapa alternatif pembelian yang ada. Dimensi dan indikator keputusan pembelian Menurut Kotler dan Keller (Rachman, 2017) menjelaskannya bahwa keputusan konsumen untuk melakukan pembelian suatu produk meliputi indikator sebagai berikut:

a. Pengenalan masalah, proses pembelian dimulai pada saat pembeli mengenali

\section{Pengaruh Kualitas Pelayanan Terhadap}

\section{Keputusan Pembelian}

Kualitas pelayanan karyawan yang baik seperti sikap ramah terhadap konsumen, pelayanan yang cepat akan membuat konsumen merasa nyaman sehingga keputusan pembelian menjadi kuat. Kualitas pelayanan baik akan membuat konsumen sebuah masalah atau kebutuhankebutuhan tersebut dapat dicetuskan oleh rangsanagan internal atau eksternal.

b. Pencarian informasi, konsumen yang tergugah kebutuhan akan terdorong untuk mencari informasi yang lebih banyak.

c. Evaluasi alternatif, model yang terbaru memandang proses evaluasi konsumen sebagai proses yang berorientasi kognitif.

d. Keputusan pembelian, dalam evaluasi alternatif, konsumen membentuk preferensi atas merek-merek dalam kumpulan pilihan.

e. Perilaku paska pembellian, menurut Kotler dan Armstrong (2012: 176) setelah mengkonsumsi suatu produk, konsumen akan mengalami tingkat kepuasan atau ketidakpuasan tertentu

betah berlama-lama menikmati produk yang ditawarkan sehingga keputusan pembelian berulang akan terjadi. Oleh karena itu dapat disimpulkan bahwa kualitas pelayanan berpengaruh terhadap keputusan pembelian. 


\section{Pengaruh Kualitas Pelayanan dan Harga Terhadap Keputusan Pembelian Pada Kedai Kirani Coffeee}

\section{Pengaruh Harga Terhadap Keputusan}

\section{Pembelian}

Perilaku konsumen dalam membeli ditentukan oleh berbagai informasi yang ia dapatkan salah satunya Harga. Dalam menentukan keputusan pembelian, informasi tentang harga merupakan hal yang sangat dibutuhkan, dimana persepsi konsumen mengenai harga suatu produk dapat dijadikan sebagai suatu standarisasi kualitas berdasarkan nilai harga pada produk tersebut. Semakin tinggi manfaat yang dirasakan oleh konsumen akan suatu Pengaruh Kualitas Pelayanan dan Harga Terhadap Keputusan Pembelian

Kualitas pelayanan yang baik dan harga yang sesuai akan mempengaruhi keputusan pembelian, semakin perusahaan memahami konsumen dari segi kualitas pelayanan dan harga maka keputusan pembelian tinggi dan sebaliknya, jika perusahaan kurang

\section{Hipotesis Penelitian}

Adapun hasil perumusan dari hipotesis di atas dapat disusun menjadi bagan sebagai berikut:

H1: Kualitas Pelayanan Berpengaruh Positif dan Signifikan Terhadap Keputasan Pembelian pada Kedai Kirani Coffee

Signifikan Terhadap Keputusan Pembelian pada Kedai KiraniCoffee.

H3: Kualitas Pelayanan dan Harga secara simultan Berpengaruh positif dan signifikan Terhadap Keputusan Pembelian pada Kedai Kirani Coffee

produk dan jasa maka akan semakin tinggi pula nilai produk tersebut. Perilaku konsumen lainnya sebelum menentukan produk mana yang akan dipilihya biasanya akan membandingkan harga di tempat lainnya, berdasarkan harga yang telah ditetapkan maka konsumen akan memutuskan untuk membeli produk yg sesuai dengan keinginannya. Sehingga dapat disimpulkan bahwa harga mempengaruhi keputusan pembelian

memahami kualitas pelayanan dan harga yang sesuai maka keputusan pembelian akan rendah. Sehingga dapat disimpulkan bahwa kualitas pelayanan dan harga mempengaruhi keputusan pembelian.

H2: Harga Berpengaruh Positif dan 


\section{METODOLOGI PENELITIAN}

Jenis penelitian ini adalah penelitian asosiatif. Penelitian asosiatif merupakan suatu pernyataan yang menunjukan dugaan tentang pengaruh antara dua variable (Ghozali, 2012). Dalam penelitian ini, penelitian asosiatif bertujuan untuk mengetahui pengaruh kualitas produk dan harga terhadap keputusan pembelian. Pada penelitian ini penulis menggunakan populasi tidak terhingga, karena jumlah populasi tidak diketahui. Populasi dalam penelitian ini adalah seluruh konsumen yang pernah berkunjung di Kedai Kirana Coffee. (Sugiyono, 2012) menjelaskan Sampel adalah bagian dari jumlah dan karakteristik yang dimiliki oleh populasii tersebut. Menurut Aminulah (2013), menyetakan bahwa jumlah sampel pada penelitian asosiatif sebanyak 50 orang. Teknik sampling yang digunakan oleh peneliti dalam penelitian ini adalah pengambilan teknik sampling purposive sampling. Purposive sampling adalah teknik penentuan sampel dengan pertimbangan tertentu, dalam penelitian ini yaitu konsumen yang pernah berkunjung di Kedai Kirana Coffee. Teknik pengumpulan data dalam penelitian ini adalah

1. Observasi adalah suatu metode atau cara untuk menganalisis dan melakukan pengamatan dan pencatatan yang dilakukan secara sistematis, tidak hanya terbatas dari orang, tetapi juga objek- objek alam yang lain (Sugiyono, 2012)

2. Angket (quisioner). Menurut (Sugiyono, 2012) bahwa "kuesioner merupakan teknik pengumpulan data yang dilakukan dengan cara memberi seperangkat pertanyaan atau pernyataan tertulis kepada responden untuk dijawabnya.

3. Studi pustaka. Studi pustaka berkaitan dengan kajian teoritis dan referensi lain yang berkaitan dengan nilai, budaya dan norma yang berkembang pada situasi sosial yang diteliti, selain itu studi pustaka sangat penting dalam melakukan penelitian, hal ini dikarenakan penelitian tidak akan lepas dari literatur-literatur ilmiah 


\section{HASIL DAN PEMBAHASAN}

\section{Uji Validitas dan Uji Reliabilitas.}

Hasil pengujian validitas variabel Kualitas validitas ini menunjukkan bahwa pernyataan Produk dan Harga dan keputusan pembelian kuesioner dalam penelitian ini dinyatakan dapat dikatakan valid pada Corrected itemvalid.

Total correlation $>0,300$. Hasil pengujian

Tabel 1. Hasil Uji Reliabilitas

\begin{tabular}{|l|c|c|c|}
\hline $\begin{array}{c}\text { Variabel dan } \\
\text { Indikator }\end{array}$ & $\begin{array}{c}\text { Cronbach's } \\
\text { Alpha }\end{array}$ & $\begin{array}{c}\text { Standar } \\
\text { Reliabilitas }\end{array}$ & ket \\
\hline $\begin{array}{l}\text { Variabel } \\
\text { Kualitas } \\
\text { Produk (X1) }\end{array}$ & 0.770 & $>0,60$ & Reliabel \\
\hline $\begin{array}{l}\text { Variabel } \\
\text { Harga (X2) }\end{array}$ & 0.838 & $>0,60$ & Reliabel \\
\hline $\begin{array}{l}\text { Variabel } \\
\text { Keputusan } \\
\text { Pembelian(Y) }\end{array}$ & 0.706 & $>0,60$ & Reliabel \\
\hline
\end{tabular}

Sumber: Data diolah, 2021

Hasil pengujian penelitian pada tabel 1 di reliabilitas ini menunjukkan bahwa atas, dapat dikatakan reliabel hal ini karena Cronbach alpha > 0,600. Hasil pengujian reliabel

\section{Uji Asumsi Klasik}

\section{a. Uji Normalitas}

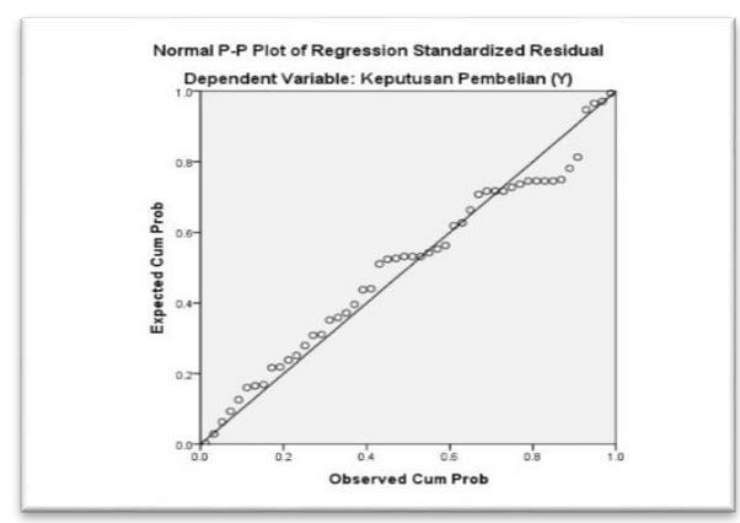

Gambar 1. Uji Normalitas 
Berdasarkan gambar 1 Uji Normalitas diatas, model regresi dalam penelitian ini berdistribusi normal. Hal ini disebabkan data ploting (titik-titik) yang menggambarkan data penelitian mengikuti garis diagonal

\section{b. Uji Multikolenearitas}

Tabel 3. Uji Multikolinearitas

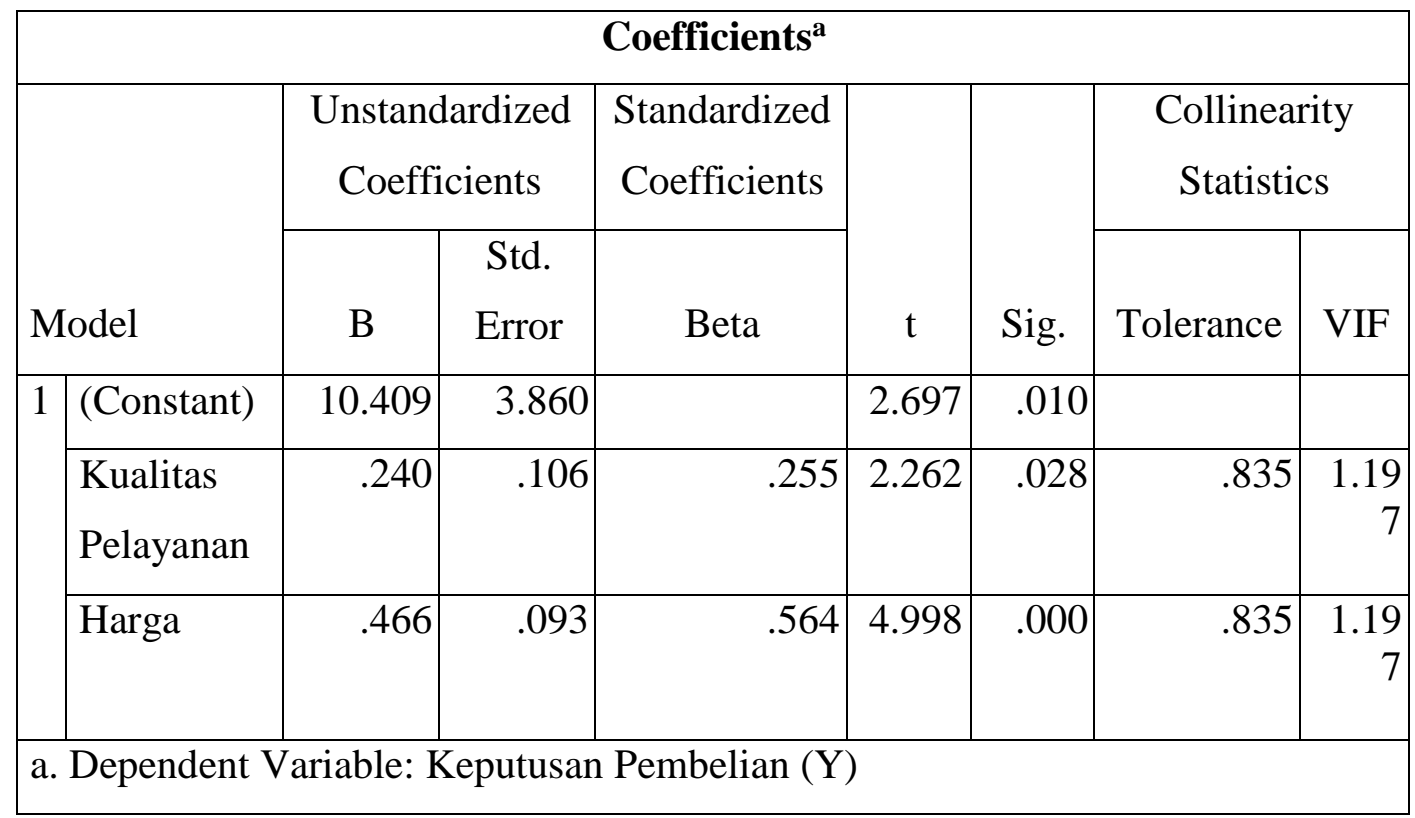

Sumber: Data diolah, 2021

Berdasarkan tabel 3 di atas bahwa tidak nilai VIF $<10,00$. Sehingga dapat terjadi gejala multikolinearitas, hal ini disimpulkan dalam penelitian ini terbebas terbukti dengan nilai tolerance $>0,10$ dan dari gejala multikolinearitas

\section{c. Uji Heteroskedasitas}

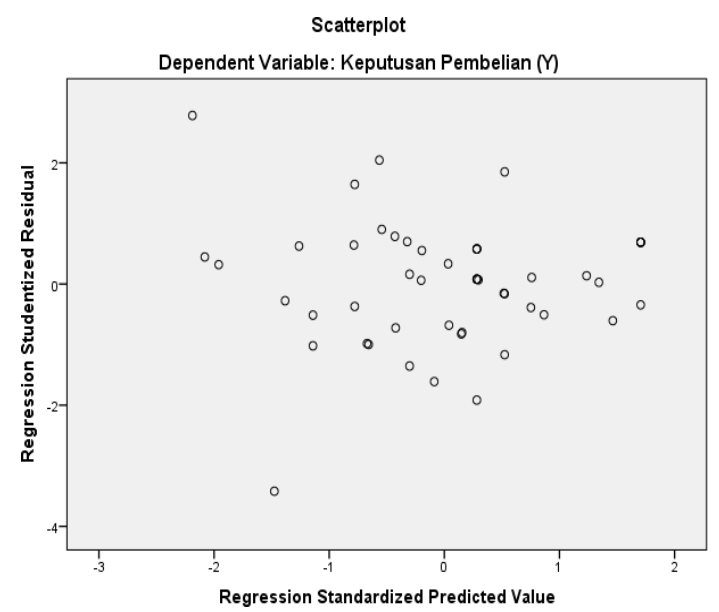

Gambar 2. Uji Heteroskedastisitas 
Pada Kedai Kirani Coffeee

Berdasarkan gambar 2. Di atas terlihat titik-titik menyebar diatas dan dibawah bahwa tidak membentuk pola tertentu angka 0 pada sumbu Y. Sehingga dapat (bergelombang, melebar kemudian disimpulkan bahwa tidak terjadi gejala menyempit) pada gambar scatterplot, serta heteroskedastisitas.

\section{d. Uji Autokorelasi}

Tabel 4. Uji Autokorelasi

\begin{tabular}{|l|r|}
\hline \multicolumn{2}{|c|}{ Runs Test } \\
\hline & \multicolumn{1}{|c|}{$\begin{array}{c}\text { Unstandardized } \\
\text { Residual }\end{array}$} \\
\hline Test Value ${ }^{\mathrm{a}}$ & .16022 \\
\hline Cases < Test Value & 24 \\
\hline Cases >= Test Value & 26 \\
\hline Total Cases & 50 \\
\hline Number of Runs & .011 \\
\hline Z & .991 \\
\hline Asymp. Sig. (2-tailed) & \\
\hline a. Median & \\
\hline
\end{tabular}

Sumber: Data Diolah, 2021

Berdasarkan uji auto korelasi maka dapat

disimpulkan bahwa tidak terdapat gejala autokorelasi, dengan demikian sehingga analisis selanjutnya dapat dilanjutkan.

\section{e. Regresi Linier Berganda}

\section{Tabel 5. Uji regresi Linear Berganda}

\begin{tabular}{|c|c|c|c|c|c|c|c|c|}
\hline \multicolumn{9}{|c|}{ Coefficients $^{\mathbf{a}}$} \\
\hline \multirow{2}{*}{\multicolumn{2}{|c|}{ Model }} & \multicolumn{2}{|c|}{$\begin{array}{c}\text { Unstandardized } \\
\text { Coefficients }\end{array}$} & \multirow{2}{*}{$\begin{array}{l}\text { Standardized } \\
\text { Coefficients } \\
\text { Beta }\end{array}$} & \multirow[b]{2}{*}{$\mathrm{t}$} & \multirow[b]{2}{*}{ Sig. } & \multicolumn{2}{|c|}{$\begin{array}{c}\text { Collinearity } \\
\text { Statistics }\end{array}$} \\
\hline & & B & $\begin{array}{l}\text { Std. } \\
\text { Error }\end{array}$ & & & & Tolerance & VIF \\
\hline 1 & (Constant) & 10.409 & 3.860 & & 2.697 & .010 & & \\
\hline & $\begin{array}{l}\text { Kualitas } \\
\text { Pelayanan }\end{array}$ & .240 & .106 & .255 & 2.262 & .028 & .835 & 1.197 \\
\hline
\end{tabular}




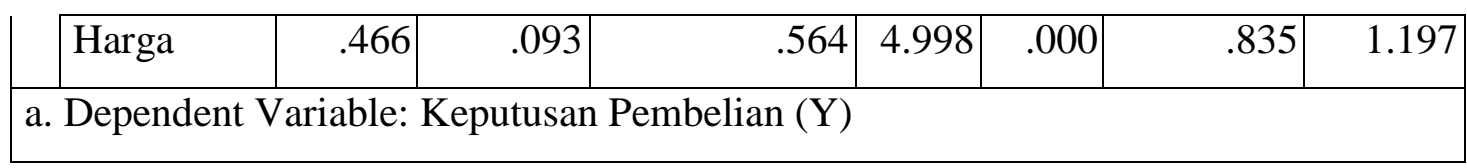

Sumber: Data diolah 2021

Persamaan regresi linier berganda:

$\mathrm{Y}=10.409+0,240 \mathrm{X} 1+0,446 \mathrm{X} 2$ Koefisien

10.409. Dimana Harga konstan maka regresi $(\mathrm{b} 1)=0,240$ artinya jika Keputusan Pembelian pada Kedai Kirani KualitasPelayanan naik sebesar $\mathrm{Rp} \quad 1$ Coffee akan naik sebesar 0,240. Koefisien Konstanta (a) $=10.409$ artinya jika Kualitas Pelayanan dan Harga konstan atau sama dengan nol maka Keputusan Pembelian pada Kedai Kirani Coffee akan naik sebesar regresi $(\mathrm{b} 2)=0,446$ artinya jika Harga naik sebesar Rp 1 dimana Kualitas Pelayanan konstan maka Keputusan Pembelian pada Kedai Kirani Coffee akan naik sebesar 0,446.

\section{f. Koefisien Korelasi Berganda}

\section{Tabel 6. Uji Koefisien Korelasi Berganda}

\begin{tabular}{|l|c|r|r|r|r|}
\hline \multicolumn{7}{|c|}{ Model Summary $^{\mathbf{b}}$} \\
\hline Model & $\mathrm{R}$ & R Square & Adjusted R Square & Std. Error of the Estimate & Durbin-Watson \\
\hline 1 & $.707^{\mathrm{a}}$ & .500 & .479 & 2.026 & 1.588 \\
\hline
\end{tabular}

Sumber: Data diolah, 2021

Nilai koefisien kolerasi berganda yaitu Harga terhadap Keputusan Pembelian berada sebesar 0,707. Artinya tingkat keeratan pada 0,60-0,799 sesuai pada tabel 7 dibawah hubungan antara Kualitas Pelayanan dan ini yang artinya kuat.

Tabel 7 . Koefisien Korelasi

\begin{tabular}{|c|c|}
\hline $\begin{array}{c}\text { Interval } \\
\text { koefisien }\end{array}$ & Tingkat hubungan \\
\hline $0,00-0,199$ & Sangat rendah \\
$0,20-0,399$ & Rendah \\
$0,40-0,599$ & Sedang \\
$0,60-0,799$ & Kuat \\
$0,80-1,000$ & Sangat kuat \\
\hline
\end{tabular}

Sumber: (Sugiyono, 2012) 
Tabel 8. Uji Determinasi

\begin{tabular}{|l|r|r|r|r|r|}
\hline \multicolumn{7}{|c|}{ Model Summary $^{\text {Model }}$} & R & R Square & $\begin{array}{c}\text { Adjusted R } \\
\text { Square }\end{array}$ & $\begin{array}{l}\text { Std. Error of } \\
\text { the Estimate }\end{array}$ & $\begin{array}{r}\text { Durbin- } \\
\text { Watson }\end{array}$ \\
\hline 1 & $\begin{array}{r}707 \\
\text { a }\end{array}$ & .500 & .479 & 2.026 & 1.588 \\
\hline
\end{tabular}

Sumber: Data diolah, 2021

Keputusan Pembelian pada Kedai Kirani $\quad 50 \%$ dipengaruhii oleh faktor-faktor lain Coffee yaitu sebesar 50\% sedangkan sisanya $\quad$ yang tidak diteliti dalam penelitian ini.

\section{g. Uii t (Uji Parsial)}

Tabel 9. Uji t

\begin{tabular}{|c|c|c|c|c|c|c|c|c|}
\hline \multicolumn{9}{|c|}{ Coefficients $^{\mathbf{a}}$} \\
\hline \multirow{2}{*}{\multicolumn{2}{|c|}{ Model }} & \multicolumn{2}{|c|}{$\begin{array}{l}\text { Unstandardized } \\
\text { Coefficients }\end{array}$} & \multirow{2}{*}{$\begin{array}{c}\begin{array}{c}\text { Standardized } \\
\text { Coefficients }\end{array} \\
\text { Beta }\end{array}$} & \multirow[b]{2}{*}{$\mathrm{t}$} & \multirow[b]{2}{*}{ Sig. } & \multicolumn{2}{|c|}{$\begin{array}{l}\text { Collinearity } \\
\text { Statistics }\end{array}$} \\
\hline & & B & $\begin{array}{l}\text { Std. } \\
\text { Error }\end{array}$ & & & & Tolerance & VIF \\
\hline \multirow[t]{3}{*}{1} & (Constant) & 10.409 & 3.860 & & 2.697 & .010 & & \\
\hline & $\begin{array}{l}\text { Kualitas } \\
\text { Pelayanan }\end{array}$ & .240 & .106 & .255 & 2.262 & .028 & .835 & $\begin{array}{r}1.19 \\
7\end{array}$ \\
\hline & Harga & .466 & .093 & .564 & 4.998 & .000 & .835 & $\begin{array}{r}1.19 \\
7\end{array}$ \\
\hline
\end{tabular}

Sumber: Data diolah, 2021

H1: Kualitas Pelayanan Berpengaruh Positif dan Signifikan Terhadap Keputasan Pembelian Pada Kedai Kirani

\section{Coffee.}

Berdasarkan table 9 diatas nilai t-hitung untuk variable Kualitas Pelayanan (X1) adalah sebesar 2.262. Nilai t-tabel $(\alpha) / 2=$ $0,05 / 2=0,025$ dan derajat bebas $(d k)=n-$ $k-1$ maka $(d k)=50-3-1=46$. Sehingga diperoleh nilai t-tabel sebesar 2.013. Sehingga 2,262>2,013 dan tingkat signifikan (Sig) > dari 0,05 yaitu Sig.0,028 $<0,05$ sehingga dapat disimpulkan bahwa hipotesis $\mathbf{H 1}$ diterima yang artinya Kualitas Pelayanan berpengaruh positif dan signifikan terhadap Keputusan Pembelian pada Kedai Kirani Coffee. Hasil penelitian ini sejalan dengan penelitian (Rachman, 


\section{Pengaruh Kualitas Pelayanan dan Harga Terhadap Keputusan Pembelian}

\section{Pada Kedai Kirani Coffeee}

Sumber: Data diolah, 2021

H3: Kualitas Pelayanan dan Harga Secara Simultan Berpengaruh Positif dan Signifikan Terhadap Keputasan Pembelian pada Kedai Kirani Coffee.

Berdasarkan hasil pengujian secara simultan pada tabel di atas. Diperoleh nilai Fhitung sebesar 23.518. Nilai Ftabel adalah sebagai berikut df $1=\mathrm{k}-1$ dan df $2=\mathrm{n}-\mathrm{k}$. jadi df $1=3-1$ $=2$, dan df $2=50-3=47$ sehingga diperoleh nilai ftabel sebesar 3.20, jadi nilai F- hitung > F-tabel dimana 23,518>3,20 dan nilai signifikan sebesar $0,000>0.05$ hal ini membuktikan bahwa hipotesis $\mathbf{H 3}$ di terima, sehingga dapat disimpulkan bahwa variabel Kualiatas Pelayanan (X1) dan Harga (X2)

\section{SIMPULAN}

Hasil penelitian menunjukkan bahwa Kualitas Pelayanan Berpengaruh Positif dan Signifikan Terhadap Keputasan Pembelian pada Kedai Kirani Coffee serta Harga Berpengaruh Positif dan Signifikan Terhadap Keputasan Pembelian pada Kedai Kirani Coffee. Secara simultan Kualitas Pelayanan dan harga Berpengaruh Positif dan Signifikan Terhadap Keputasan Pembelian pada Kedai Kirani
Secara Simultan Berpengaruh positif dan signifikan Terhadap Keputusan Pembelian (Y) pada Kedai Kirani Coffee. Hasil penelitian ini sejalan dengan penelitian Danny (2017) yang menyatakan bahwa secara bersama-sama kualitas pelayanan harga bepengaruh poitif dan signifikan terhadap keputusan pembelian pada rumah makan wajan warung kudus. Dan penelitian lain yang sejalan yaitu penelitian (Irzaldi, Yazid, Hidaya, \& Wahyu, 2020) menyatakan bahwa secara bersama-sama kualitas pelayanan dan harga bepengaruh positif dan signifikan terhadap keputusan pembelian Apotek K-24 Gadjah Mada.

Coffee. Untuk saran, Kedai Kirani Coffee perlu mempertahankan kualitas pelayanan dan harga yang sesuai dengan produk yang ditawarkan sehingga keputusan pembelian konsumen menjadi lebih meningkat. Bagi peneliti selanjutnya dapat dijadikan referensi untuk peneitian selanjutnya dengan menambah variabel lain yang mempengaruhi keputusan pembelian. 
Jurnal Bina Manajemen, September 2021, Vol. 10, No. 1 Hal 229 - 245

\section{DAFTAR PUSTAKA}

Aisyah, S., Agustiawan, A., Nurwanita, \& Fatma, F. (2020). Pengaruh Kualitas Produk dan Desain Terhadap Keputusan Pembelian Motor Yamaha Vixion. Jurnal Ilmu Ekonomi dan Bisnis Islam - JIEBI Vol. 2 No1, 60-75.

Ghozali, I. (2012). Aplikasi Analisi Multivarian dengan Program SPSS. Semarang: BPUNDIP.

Irzaldi, Yazid, Hidaya, \& Wahyu. (2020). Pengaruh Kualitas Pelayanan Dan Harga Terhadap Keputusan Pembelian (Apotek K-24 Jl. Gadjah Mada Yogyakarta). urnal Ilmu Administrasi Bisnis, Vol. 9, No. 1, 305-314.

Kurniawan, F. Y., \& Sari, D. (2017). Pengaruh Kualitas Produk, Harga, Dan Kepercayaan Terhadap Proses Keputusan Pembelian Konsumen Perusahaan Konveksi Inglorious Industries $\mathrm{Di}$ Kota Bandung. eProceeding of Management : Vol.4, No.1, ISSN : 2355-9357, 735-744.
Octaviani, N. (2013). Pengaruh Kualitas Pelayanan Terhadap Kepuasan Pelanggan Kafe Kopi Miring Semarang. Jurusan Ekonomi Manajemen, Universitas Dian Nuswantoro.

Rachman, D. A. (2017). Pengaruh Kualitas Pelayanan Dan Harga Terhadap Keputusan Pembelian (Studi Kasus Pada Rumah Makan Wajan Mas Kudus). Diponegoro. Diponegoro Journal Of Social And Political Science, 1-8.

Riyono, \& Budiharja, G. E. (2016). Pengaruh Kualitas Produk, Harga, Promosi Dan Brand Image Terhadap Keputusan Pembelian Produk Aqua Di Kota Pati. Jurnal Stie Semarang, VOL 8, NO 2, Edisi Juni 2016, 92-121.

Sugiyono. (2012). Metode Pendekatan Penelitian Kuantitatif-Kualitatif. Bandung: Alfabeta. 